\title{
Production of serum antibodies that recognise epitopes located on the R3 region of Escherichia coli core lipopolysaccharides by patients infected with strains of enterohaemorrhagic $E$. coli
}

\author{
HENRIK CHART, THOMAS CHEASTY and GERALDINE A. WILLSHAW \\ Laboratory of Enteric Pathogens, Division of Gastrointestinal Infections, Central Public Health Laboratory, \\ 61 Colindale Avenue, London NW9 5HT
}

\begin{abstract}
Antibody-antigen cross-reactions were examined with sera from patients with Escherichia coli 0157 infection and lipopolysaccharide (LPS) purified from a range of enterohaemorrhagic $E$. coli (EHEC) including those belonging to serogroups 026,0103 , O111, 0145 and 0157 . Six of 10 patients infected with an 0157 EHEC produced serum antibodies that cross-reacted with common LPS-core epitopes, which were expressed by 23 of 33 strains of EHEC examined. These common LPS-core epitopes were also present on strains of $E$. coli $\mathrm{O} 26$ which did not produce verocytotoxin. These cross-reacting antibodies did not influence the basic immunoblotting procedures used for the routine serodiagnosis of infections with $E$. coli 0157.
\end{abstract}

\section{Introduction}

Verocytotoxin-producing Escherichia coli (VTEC), and particularly strains of serotype O157:H7, are recognised as a major cause of diarrhoea, bloody diarrhoea and haemolytic uraemic syndrome (HUS) in North America [1] and the UK [2]. Certain other VTEC, and in particular those belonging to serogroups O26, O103, O111 and O145 [3], also cause a disease characterised by bloody diarrhoea, which may develop into HUS [4]. These strains, together with $\mathrm{O} 157$ strains, have been termed enterohaemorrhagic E. coli (EHEC) $[1,5]$.

Patients infected with VTEC O157 produce serum antibodies to the 0157 lipopolysaccharide (LPS) antigens [6-9], and these antibodies form the basis for routine serological tests providing evidence of infection in the absence of faecal isolates of $E$. coli O157 [10, 11]. The interpretation of serological results relies on a knowledge of antibody cross-reactions with the LPS antigens of other members of the Enterobacteriaceae and these have been examined extensively [12-16].

Strains of E. coli express LPS with a core region comprising one of five different structures, termed R1,

Received 5 Feb. 2002; accepted 26 June 2002.

Corresponding author: Dr H. Chart (e-mail: hchart@phls. org.uk).
R2, R3, R4 and K-12 [17], and it has been suggested that the majority of EHEC express the R3 LPS-core structure [17]. Based on this, it was reported that human serum antibodies binding to R3 core oligosaccharides of $E$. coli 0157 LPS might cause antibody cross-reactions between the LPS of E. coli O157 and other EHEC [18] and, because of this, antibodies to $E$. coli 0157 LPS detected in patients' sera should be interpreted with caution. In the present study, LPS was prepared from a range of EHEC, including strains belonging to serogroups $\mathrm{O} 26, \mathrm{O} 103, \mathrm{O} 111, \mathrm{O} 145$ and O157, to examine the binding of human serum antibodies to epitopes thought to be located on the R3 LPS-core.

\section{Materials and methods}

\section{Bacterial strains and culture conditions}

Strains of VTEC used in this study (Table 1) were isolated from cases of HUS and some of these have been described previously [19]. Strains of E. coli belonging to serogroup O157 express LPS producing one of three different LPS profiles - A, B and C - by SDS-PAGE [20]; only strains expressing profile C produce VT [20]. E. coli strains O157:H19 (E10964) and E. coli O157:H45 (E59055) were VT-negative strains expressing 0157 LPS profiles A and B respectively. These two strains express LPS profiles which bind rabbit antibodies used for detecting strains 
of $E$. coli belonging to serogroup O157. Ten further strains of E. coli O26:H11 were also used (Table 2) [21], five of these strains were VTEC and five did not express VT [21]. Strains of Yersinia enterocolitica O9 (E4610) [14], Vibrio cholerae O1 Inaba (SC1074) [15], Citrobacter freundii (E69366) [16] and Salmonella enterica serotype Urbana (S127490) [16] were also used to prepare LPS. These strains had been shown to express LPS which shared epitopes with E. coli 0157 $[14,16]$. The strain of $S$. Urbana was a representative of the group N Salmonella [16]. All bacteria were from the culture collection held by the Laboratory of Enteric Pathogens (LEP). Bacteria were grown on nutrient agar (Oxoid) at $37^{\circ} \mathrm{C}$ for $16 \mathrm{~h}$.

\section{Sera}

Sera with antibodies to the LPS of E. coli O157 were from 10 patients with clinical HUS and from whom

Table 1. Strains of VTEC used in this study

\begin{tabular}{|c|c|c|}
\hline Strain no. & Serotype & $\begin{array}{l}\text { LPS-core binding } \\
\text { antibodies to O157* }\end{array}$ \\
\hline E89960 & O9ab:H $\mathrm{H}^{-}$ & - \\
\hline E59645 & $\mathrm{O} 26: \mathrm{H}^{-}$ & + \\
\hline E36039 & O26:H11 & + \\
\hline E43938 & O55:H10 & - \\
\hline E45037 & O91:H21 & - \\
\hline E05276 & $\mathrm{O} 103: \mathrm{H} 2$ & + \\
\hline E32627 & $\mathrm{O} 104: \mathrm{H} 2$ & + \\
\hline E43549 & O105ac:H18 & + \\
\hline E55391 & O111ac:H $H^{-}$ & + \\
\hline $\mathrm{E} 45035$ & O111ac:H- & + \\
\hline E45038 & O111ac:H- & + \\
\hline E45040 & O111ac:H $\mathrm{H}^{-}$ & + \\
\hline E48973 & O111ac:H $\mathrm{H}^{-}$ & + \\
\hline E52849 & O111ac:H $\mathrm{H}^{-}$ & + \\
\hline E47748 & O115:H10 & - \\
\hline E40135 & O128ab:H25 & - \\
\hline E92568 & O134:H25 & - \\
\hline E34683 & $\mathrm{O} 145: \mathrm{H} 25$ & + \\
\hline E38938 & $\mathrm{O} 145: \mathrm{H} 25$ & + \\
\hline E72609 & $\mathrm{O} 145: \mathrm{H} 25$ & + \\
\hline E31695 & O153:H25 & + \\
\hline E32511 & $\mathrm{O} 157: \mathrm{H}^{-}$ & + \\
\hline E31708 & O163:H19 & - \\
\hline E45324 & O163:H19 & - \\
\hline E46091 & $\mathrm{O} 165: \mathrm{H} 25$ & + \\
\hline E61936 & $\mathrm{O} 168: \mathrm{H}^{-}$ & - \\
\hline E80184 & O173:H21 & - \\
\hline E31705 & O-rough:H51 & + \\
\hline
\end{tabular}

* The six human sera described in Results as having antibodies to LPS-core were used. faecal O157 VTEC had been isolated and form part of the LEP collection. Six were from female (mean age: 3 years 6 months) and three were from male (mean age: 3 years 3 months) patients. Sera from two girls with HUS (1 year 8 months, E134825; 9 years 6 months, E160315) were also used in this study and O26 VTEC was isolated from the faeces of both patients. Sera from 10 blood donors were provided by the North London Blood Transfusion Centre and used as controls.

Antisera were prepared in New Zealand White rabbits to LEP type-strains of $E$. coli belonging to serogroups O26, O103, O111, O145 and O157 [22]. Rabbits received $0.5 \mathrm{ml}$ (i.v.) of a heat-killed bacterial suspension $\left(10^{9}\right.$ bacteria/ml $)$ on day $1 ; 1 \mathrm{ml}$ (i.v.) on days 5 and 10 , and $2 \mathrm{ml}$ (i.v.) on days 15 and 20. Rabbits were bled on day 30 . All sera were stored at $-30^{\circ} \mathrm{C}$.

\section{$L P S$}

LPS was prepared by digesting whole bacterial cells with proteinase- $K$ [6]. Bacteria were placed in preweighed $1.5-\mathrm{ml}$ plastic tubes and the cells were suspended in SDS-PAGE sample buffer [23] to give a concentration of $1 \mathrm{mg} / 30 \mu \mathrm{l}$ before incubation at $100^{\circ} \mathrm{C}$ for $10 \mathrm{~min}$. After cooling, samples were mixed with an equal volume of SDS-PAGE buffer containing proteinase $\mathrm{K}$ (Sigma) $100 \mu \mathrm{g} / 30 \mu \mathrm{l}$ and incubated at $60^{\circ} \mathrm{C}$ for $1 \mathrm{~h}$.

\section{SDS-PAGE and immunoblotting}

For SDS-PAGE, preparations containing $500 \mu \mathrm{g}$ of digested cell mass were used in each lane. Samples were loaded on to gels (4.5\% stacking gel and $12.5 \%$ separation gel) and electrophoresis was performed at 50 $\mathrm{mAmp}$ for $2.25 \mathrm{~h}$ [6]. Gels were either stained with silver to show LPS profiles [24] or profiles were transferred on to nitrocellulose paper (NCP) electrophoretically (0.50 Amp, $1 \mathrm{~h})$ [6]. NCP sheets were blocked with skimmed milk $3 \%$ in phosphate-buffered saline (PBS) for $30 \mathrm{~min}$ and exposed to sera (30 $\mu \mathrm{l} /$ lane) for $60 \mathrm{~min}$. After washing with PBS three times (10 min each), profiles were treated with either goat anti-human polyvalent Ig conjugated with alkaline phosphatase (Sigma) $5 \mu \mathrm{l} /$ lane or goat anti-rabbit IgM

Table 2. Strains of E. coli belonging to serotype O26:H11

\begin{tabular}{llccc}
\hline Strain no. & Source & VT & Enterohaemolysin & $\begin{array}{c}\text { Antibodies binding } \\
\text { to core LPS* }\end{array}$ \\
\hline E6175/0 & Bovine & VT1 & + & + \\
E6177/0 & Bovine & VT1 & - & + \\
E7515/0 & Bovine & - & - & + \\
E33382/0 & Human & VT1 & + & + \\
E34063/0 & Human & VT1 & + & + \\
E52757/0 & Human & VT1 & + & + \\
E35363/0 & Human & - & - & + \\
E38984/0 & Human & - & + & + \\
E42080/0 & Human & - & - & + \\
E21427/0 & Human & - & + & + \\
\hline
\end{tabular}

*Antibodies in a human serum infected with E. coli O157 binding to LPS core thought to be R3. 
(Southern Biotechnology Associates, USA) $5 \mu \mathrm{l} /$ lane in skimmed milk-PBS for $60 \mathrm{~min}$. After washing, as above, profiles were placed in substrate buffer (0.1 M Tris, $\quad 0.09 \mathrm{M} \mathrm{NaCl}, \quad 0.15 \mathrm{M} \mathrm{Mg}_{2} \mathrm{Cl}_{6} 6 \mathrm{H}_{2} \mathrm{O}$ ) for $10 \mathrm{~min}$. For colour development, NCP strips were placed in $10 \mathrm{ml}$ of substrate buffer containing $45 \mu \mathrm{l}$ of nitroblue tetrazolium (Sigma; $75 \mathrm{mg} / \mathrm{ml}$ in $70 \%$ aqueous dimethyl formamide) and $35 \mu \mathrm{l}$ of 5-bromo-4chloro-3-indolylphosphate. $\mathrm{Na}_{2}$ (Sigma; $50 \mathrm{mg} / \mathrm{ml}$ in de-ionised water).

\section{Results}

\section{SDS-PAGE and immunoblotting}

Initially, five strains of $E$. coli belonging to serotypes O26:H11 (E36039), O103:H2 (E05276), O111: $\mathrm{H}^{-}$ (E52849), O145:H25 (E38938) and O157: $\mathrm{H}^{-}$ (E32511) were examined; all expressed long-chain LPS as detected by SDS-PAGE and silver staining (Fig. 1 , lanes 1-5). When these profiles were exposed to sera from patients infected with O157 VTEC, antibodies bound to the long-chain LPS components of O157 LPS (Fig. 1, lane 10) in sera from all 10 patients. However, six of the patients were also shown to have antibodies that bound to the core region only of the remaining LPS preparations (Fig. 1, lanes 6-9).

Profiles of the five preparations of LPS were also treated with rabbit antibodies prepared to E. coli O26, O103, O111, O145 and O157. The sera reacted with the homologous LPS preparations only and antibodies did not bind to the core region of the heterologous LPS preparations (not shown). Human serum antibodies binding to the core region of EHEC LPS did not bind to the core LPS of VT-negative strains of O157:H19 (E10964) expressing O157 LPS profile A, or E. coli O157:H45 (E59055) expressing O157 LPS profile B

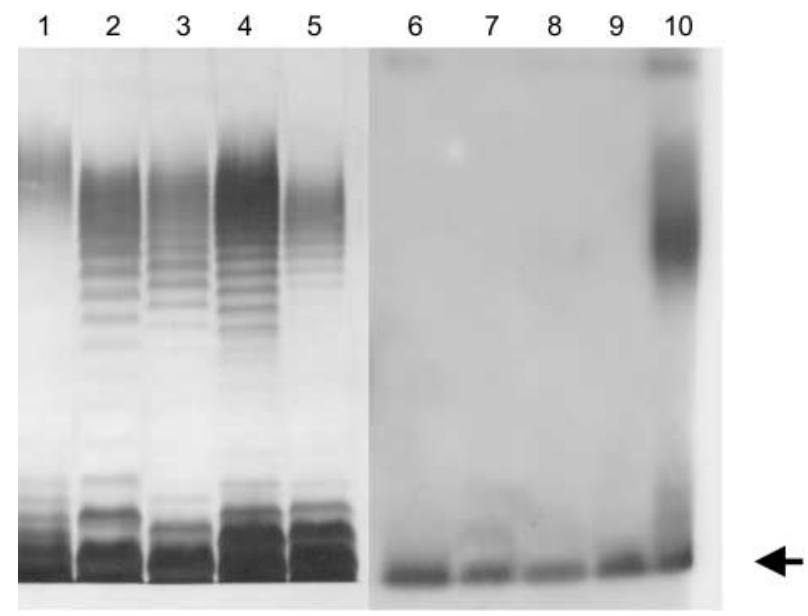

Fig. 1. The five strains of $E$. coli belonging to serogroups O26, O103, O111, O145 and O157 expressed long-chain LPS as detected by SDS-PAGE and silver staining (lanes 1-5). Patients' serum antibodies bound to the core LPS of all five strains (arrow) (lanes 6-10), but bound only to long-chain LPS expressed by E. coli $\mathrm{O} 157$ (lane 10). (not shown). Similarly, the core-binding antibodies did not bind to the LPS profiles from strains of $Y$. enterocolitica O9 (E4610), $V$. cholerae O1 Inaba (SC1074), S. Urbana (S127490) or C. freundii (E69366). The 10 control sera did not contain antibodies to long-chain LPS or core regions of any of the LPS preparations used.

The LPS preparations from the remaining 23 strains of EHEC listed in Table 1 were also exposed to six sera from patients with antibodies to E. coli O157 LPS containing antibodies to the core region of five LPS types described above. The core-LPS of 13 of the 23 strains bound antibodies present in the patients' sera (Table 1). These 13 strains comprised five strains belonging to serogroup O111, and strains belong to serogroups O26, O104, O105ac, O145(2), O153 and O165. The antibodies also bound to the core-LPS of strain E31705 that did not express long-chain LPS.

Immunoblots, resulting from the routine serodiagnosis of 600 patients shown not to have produced serum antibodies to O157 LPS, were examined for antibodies binding to the LPS core-region, thought to be R3. Only two were detected (E134825 and E160315). Both were from young girls with HUS and VTEC O26 had been isolated from both patients. When LPS profiles prepared from E. coli strains O26, O103, O111, $\mathrm{O} 145$ and $\mathrm{O} 157$ were exposed to these sera, antibodies were found to bind to the core LPS of all five strains, but only to the long-chain LPS of E. coli O26. The presence of the common LPS-core region, thought to be R3, in strains of E. coli O26:H11 was examined further with five strains of EHEC and five non-VTEC strains of O26:H11 (Table 2). All 10 strains were found to bind human antibodies to the LPS R3 core region.

\section{Discussion}

The observation that patients' antibodies also bound to the core of the LPS prepared from the non-O157 EHEC strains examined supported the theory that certain EHEC have shared core components, thought to be the R3 core region $[17,18,25]$. These antibodies did not bind to the core LPS from E. coli O157:H19 (E10964) and E. coli O157:H45 (E59055) showing that the core epitopes were associated with EHEC O157 and were not merely a common property of strains of E. coli belonging to this serogroup.

The five EHEC LPS profiles prepared from strains of O26, O103, O111, O145 and O157 were shown to bind homologous antibodies raised in rabbits [26], but these rabbit sera did not contain antibodies to the shared LPS-core epitopes. The type-strains of E. coli used to prepare the rabbit sera to $\mathrm{O} 26, \mathrm{O} 103, \mathrm{O} 111$ and $\mathrm{O} 145$ were isolated in the early $1950 \mathrm{~s}$ and $1960 \mathrm{~s}$, and the precise source of these strains is unknown; the typestrain of E. coli $\mathrm{O} 157$ was isolated from a piglet [27]. 
These type-strains did not carry the genes encoding VT.

In addition to the five $E$. coli strains belonging to serotypes O26:H11, O103:H2, O111: $\mathrm{H}^{-}, \mathrm{O} 145: \mathrm{H} 25$ and $\mathrm{O} 157: \mathrm{H}^{-}, 13$ other strains also bound core-LPS antibodies present in six of the 10 human sera and these included five belonging to serogroup O111, and strains of serogroups O26, O104, O105ac, O145, O153, O165 and O-rough. Ten of the 28 strains did not bind the antibodies directed at core-LPS, indicating that not all VTEC or EHEC have the common (R3) core epitopes. The strain of O55:H10 used in this study did not bind antibodies directed at LPS-core, although Amor et al. [17] detected R3 core-LPS in a strain of VTEC belonging to serotype O55:H7. A study examining antibody cross-reactions between $E$. coli O157 and 19 strains of $E$. coli O55 with a range of flagellar types [28] did not detect binding of human serum antibodies specific for O157 LPS to the LPS of any of the O55 strains tested. This suggested that the R3 core might be expressed only rarely by strains of $E$. coli O55. The patients' antibodies did not bind to the LPS of strains of $Y$. enterocolitica $09, V$. cholerae $\mathrm{O} 1$ Inaba, $S$. Urbana or $C$. freundii, indicating that the epitopes on the R3 core were not present on these bacteria either.

Two sera were shown to contain antibodies binding to the LPS core, thought to be R3, but not to long-chain O157 LPS. The patients from whom these two sera were obtained both developed HUS and were subsequently found to have been infected with strains of $E$. coli $\mathrm{O} 26: \mathrm{H} 11$ with genes encoding VT2, and VT1 and VT2, respectively. Strains of VTEC and non-VTEC O26:H11 were shown to have the cross-reacting LPS core region, indicating that this was a common feature of strains belonging to this serotype, irrespective of whether they were VTEC or not.

The R1, R2, R3, R4 and K-12 LPS core structures have been partially elucidated $[17,29]$ and strains of $E$. coli with R3 core share an inner core sugar - 3-deoxy-Dmanno-oct-2-ulsonic acid (Kdo) - with strains of Salmonella spp. [29]. However, as patients' serum antibodies binding to EHEC LPS did not bind to the core of $S$. Urbana, this moiety of the core was not thought to be involved in antibody binding. The outercore region of R3 E. coli LPS contains arrangements of glucose and $\mathrm{N}$-acetyl-glucosamine [28] which are likely to be involved in antibody binding; however, the precise role of these components in forming the common R3 epitope(s) remains to be determined.

Sera from patients infected with O157 VTEC did not contain antibodies binding to the long-chain LPS of O26, O103, O111 and O145; therefore, it was concluded that the presence of shared R3 epitopes would not influence the results of routine serology. Furthermore, because only two of 600 sera from patients shown not to have antibodies to O157 LPS expressed antibodies binding to the LPS core-region, it is concluded that human serum antibodies to the R3 core, other than that of O157 VTEC, are rare. It was demonstrated in this study that routine serodiagnosis of infections with $E$. coli O157, with an established immunoblotting procedure [8], continues to be a reliable method of providing evidence of infection with E. coli $\mathrm{O} 157$ in the absence of faecal isolates of O157 VTEC.

\section{References}

1. Besser RE, Griffin PM, Slutsker L. Escherichia coli O157:H7 gastroenteritis and the hemolytic uremic syndrome: an emerging infectious disease. Annu Rev Med 1999; 50: 355-367.

2. Willshaw GA, Cheasty T, Smith HR, O'Brien SJ, Adak GK. Verocytotoxin-producing Escherichia coli (VTEC) 0157 and other VTEC from human infections in England and Wales: 1995-1998. J Med Microbiol 2001; 50: 135-142.

3. Gyles C, Johnson R, Gao A et al. Association of enterohemorrhagic Escherichia coli hemolysin with serotypes of Shiga-like toxin-producing Escherichia coli of human and bovine origins. Appl Environ Microbiol 1998; 64: 4134-4141.

4. Chart H. Clinical significance of Verocytotoxin-producing Escherichia coli O157. World J Microbiol Biotech 2000; 16: 719-724.

5. Levine MM, Xu J-G, Kaper JB et al. A DNA probe to identify enterohaemorrhagic Escherichia coli of 0157:H7 and other serotypes that cause hemorrhagic colitis and hemolytic uremic syndrome. J Infect Dis 1987; 156: 175-182.

6. Chart H, Scotland SM, Rowe B. Serum antibodies to Escherichia coli serotype O157:H7 in patients with hemolytic uremic syndrome. J Clin Microbiol 1989; 27: 285-290.

7. Chart H, Smith HR, Scotland SM, Rowe B, Milford DV, Taylor CM. Serological identification of Escherichia coli O157:H7 infection in haemolytic uraemic syndrome. Lancet 1991; 337: $138-140$.

8. Chart H, Jenkins C. The serodiagnosis of infections caused by Verocytotoxin-producing Escherichia coli. J Appl Microbiol 1999; 86: $731-740$

9. Jenkins C, Chart H. Serodiagnosis of infection with Verocytotoxin-producing Escherichia coli. J Appl Microbiol 1999; 86: $569-575$.

10. Thomas A, Chart H, Cheasty T, Smith HR, Frost JA, Rowe B. Vero cytotoxin-producing Escherichia coli particularly serogroup O157, associated with human infections in the United Kingdom: 1989-91. Epidemiol Infect 1993; 110: 591-600.

11. Thomas A, Cheasty T, Frost JA, Chart H, Smith HR, Rowe B. Vero cytotoxin-producing Escherichia coli particularly serogroup O157, associated with human infections in England and Wales: 1992-4. Epidemiol Infect 1996; 117: 1-10.

12. Chart H, Rowe B. Antibody cross-reactions with lipopolysaccharides from E. coli $\mathrm{O} 157$ after cholera vaccination. Lancet 1993; 341: 1282

13. Chart H, Cheasty T, Cope D, Gross RJ, Rowe B. The serological relationship between Yersinia enterocolitica O9 and Escherichia coli $\mathrm{O} 157$ using sera from patients with yersiniosis and haemolytic uraemic syndrome. Epidemiol Infect 1991; 107: 349-356.

14. Chart H, Okubadejo OA, Rowe B. The serological relationship between Escherichia coli $\mathrm{O} 157$ and Yersinia enterocolitica $\mathrm{O} 9$ using sera from patients with brucellosis. Epidemiol Infect 1992; 108: 77-85.

15. Chart H, Willshaw GA, Cheasty T, Rowe B. Structure and antigenic properties of Citrobacter freundii lipopolysaccharides. J Appl Bacteriol 1993; 74: 583-587.

16. Chart H, Cheasty T, Georgiou T, Rowe B. Antigenic crossreactions between Escherichia coli O157, Vibrio cholerae O1 (Inaba) and group N Salmonella. Serodiag Immunother Infect Dis 1993; 5: 81-84.

17. Amor K, Heinrichs DE, Frirdich E, Ziebell K, Johnson RP, Whitfield C. Distribution of core oligosaccharide types in lipopolysaccharides from Escherichia coli. Infect Immun 2000; 68: $1116-1124$. 
18. Currie CG, McCallum K, Poxton IR. Mucosal and systemic antibody responses to the lipopolysaccharide of Escherichia coli $\mathrm{O} 157$ in health and disease. J Med Microbiol 2001; 50: 345-354.

19. Willshaw GA, Scotland SM, Smith HR, Rowe B. Properties of Vero cytotoxin-producing Escherichia coli of human origin of O serogroups other than O157. J Infect Dis 1992; 166: 797-802.

20. Chart H, Said B, Stokes N, Rowe B. Heterogeneity of lipopolysaccharides by strains of Escherichia coli O157. J Infect 1993; 27: 237-241.

21. Scotland SM, Willshaw GA, Smith HR, Rowe B. Properties of strains of Escherichia coli $\mathrm{O} 26: \mathrm{H} 11$ in relation to their enteropathogenic or enterohemorrhagic classification. $J$ Infect Dis 1990; 162: 1069-1074.

22. Chart H, Frost JA, Oza A. Thwaites, R, Gillanders S, Rowe B. Heat-stable serotyping antigens expressed by strains of Campylobacter jejuni are probably capsular and not long-chain lipopolysaccharides. J Appl Bacteriol 1996; 81: 635-640.

23. Laemmli UK. Cleavage of structural proteins during the assembly of the head of bacteriophage T4. Nature 1970;
227: $680-685$.

24. Tsai C-M, Frasch CE. A sensitive silver stain for detecting lipopolysaccharides in polyacrylamide gels. Anal Biochem 1982; 119: 115-119.

25. Currie CG, Poxton IR. The lipopolysaccharide core type of Escherichia coli $\mathrm{O} 157: \mathrm{H} 7$ and non-O157 verocytotoxin-producing E. coli. FEMS Immunol Med Microbiol 1999; 24: 57-62.

26. Chart H, Rowe B. Serological identification of infection by Vero cytotoxin producing Escherichia coli in patients with haemolytic uraemic syndrome. Serodiag Immunother Infect Dis 1990; 4: 413-418.

27. Sweeney EJ. Strains of Escherichia coli associated with mortality in pigs. Irish Vet $J$ 1970; 24: 108-113.

28. Chart H, Jenkins C, Smith HR, Rowe B. Strains of Escherichia coli belonging to serogroups $\mathrm{O} 157$ and O55 express lipopolysaccharides that are structurally distinct and do not share common epitopes. J Infect Dis 1998; 178: 920-921.

29. Heinrichs DE, Yethon JA, Whitfield C. Molecular basis for structural diversity in the core regions of the lipopolysaccharides of Escherichia coli and Salmonella enterica. Mol Microbiol 1998; 30: 221-232. 